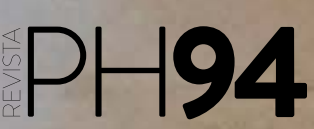

investigación

Monográficco El patrimonio paleontológico español coordina Bienvenido Martínez-Navarro

El presente volumen de revista $\mathrm{PH}$ está dedicado al patrimonio paleontológico de España. En él se describe, desde la perspectiva de profesionales cualificados, investigadores y académicos de larga trayectoria profesional y reconocida experiencia, la importancia de los registros fósiles de nuestro país, tanto marinos como continentales. Con ello se pretende explicar, en el contenido de un número monográfico, las principales cuencas sedimentarias y yacimientos de las distintas épocas de la historia geológica en la Península Ibérica.

En esta representación general del patrimonio paleontológico, esperamos no haber olvidado algún referente importante. Si así ha sido, pedimos disculpas por anticipado. Si se ha obviado algún afloramiento o yacimiento paleontológico cuyo valor patrimonial no ha sido citado, en ningún caso, dichas potenciales omisiones han ocurrido de manera deliberada y, como coordinador de este monográfico, asumo toda la responsabilidad.

Este volumen comienza con un capítulo, realizado por José Manuel García Aguilar y sus colaboradores de la Universidad de Málaga, sobre los condicionantes geológicos que permiten la formación de los yacimientos con fósiles en los distintos paleoambientes. Además informa sobre la legislación española relacionada con el patrimonio geológico.

Continúa con una revisión general sobre el patrimonio paleontológico en registros marinos de la Península Ibérica, por Eustoquio Molina, de la Universidad de Zaragoza, y sus colaboradores adscritos a diversas universidades españolas. En este capítulo nos muestran, de manera muy documentada, las principales series estratigráficas con sus principales especies fósiles y su localización, incluyendo el Paleozolico (que abarca los diferentes periodos de la era Primaria: Cámbrico, Ordovício, Silúrico, Devónico, Carbonífero y Pérmico), el Mesozoico (que incluye el Triásico, Jurásico y Cretácico) y el Cenozoico (con el Paleógeno y el Neógeno).

Sigue un capítulo sobre los registros de dinosaurios en España y Portugal por Luis Alcalá y sus colaboradores de la Fundación Dinópolis en Teruel, en el que nos informan sobre los extraordinarios yacimientos presentes en la Península Ibérica, sobre la historiografía de los hallazgos y, finalmente, sobre el estado actual de este patrimonio de cara a su explotación cultural y turística, destacando el éxito de Dinópolis.

El siguiente capítulo está dedicado a los registros con aves fósiles, por Antonio Sánchez Marco, adscrito al Institut Català de Paleontologia "Miquel Crusafont", de Bellaterra-Sabadell, en el que nos documenta sobre el registro de estos vertebrados con plumas, desde su aparición en el Mesozoico hasta los extraordinarios registros cuaternarios, tanto en la Península como en las islas.

En el capítulo siguiente, saltándonos el Paleogeno continental que, aunque interesante, los registros continentales no son muy abundantes, pasamos al Neógeno, concretamente a su parte basal, el Mioceno, que abarca desde hace 23 hasta hace 5,3 millones de años, donde Jordi Agustí, del ICREA-IPHES de 


\title{
Monográfico El patrimonio paleontológico español
}

\author{
coordina Bienvenido Martínez-Navarro
}

Tarragona, nos ilustra con una visión general cronológica del interesante patrimonio registrado en las grandes cuencas continentales, tales como las del Ampurdán, Vallés-Penedés, Calatayud-Teruel, Cabriel, las cuencas intrabéticas como la de Baza y Guadix, o las intramesetarias del Duero y del Tajo. Entre ellos, destacamos los interesantes hallazgos de simios fósiles en los yacimientos catalanes del Vallés-Penedés, como Can Llobateres al lado de Sabadell o el vertedero de Can Mata en Hostalets de Pierola, o de los espectaculares hallazgos de fauna con grandes carnívoros en el yacimiento del Cerro de los Batallones en la localidad madrileña de Torrejón de Velasco.

El monográfico concluye con un capítulo dedicado a los yacimientos continentales del Plioceno y Cuaternario (últimos 5,3 millones de años), realizado conjuntamente con mis colaboradores de la Universidad de Málaga y del Institut Català de Paleontología "Miquel Crusafont", en el que intentamos resumir la enorme cantidad de información sobre el patrimonio paleobiológico de los principales yacimientos españoles en cuencas sedimentarias como las de Besalú-Bañolas, Vallés-Penedés, Calatayud-Teruel y, especialmente, la cuenca intrabética de Baza y Guadix, donde se encuentra el registro más continuado y mejor conservado de todo el Plio-Pleistoceno del continente europeo, con especial referencia al yacimiento pliocénico de Baza 1 y a los yacimientos del Pleistoceno inferior de Orce, tales como Venta Micena, Fuente Nueva 1 y 3 , o Barranco León. Por supuesto, se citan también las acumulaciones en los maares, que son las cuencas que se forman en los cráteres volcánicos, como el del Camp dels Ninots en la localidad catalana de Caldas de Malavella, o el de Las Higueruelas en la Mancha, así como los registros en las terrazas fósiles de los ríos y, especialmente, las acumulaciones en los extraordinarios sistemas kársticos, tan abundantes en toda la Pénínsula Ibérica, entre los que destaca por la espectacularidad de los hallazgos allí realizados el de la Sierra de Atapuerca en Burgos.

Espero que este paseo por el patrimonio paleontológico español sea de su agrado y aprovecho para reiterar mis disculpas por las omisiones que se hayan realizado.

Bienvenido Martínez-Navarro | IPHES, Institut Català de Paleoecologia Humana i Evolució Social, Àrea de Prehistòria, Universitat Rovira i Virgili (URV), ICREA 